\title{
Morbidity patterns among medical admissions at Niger Delta University Teaching Hospital, Bayelsa State, Nigeria
}

\author{
Oghenekaro Godwin Egbi \\ Department of Internal Medicine, Niger Delta University Teaching Hospital, Okolobiri, Bayelsa State, \\ Nigeria
}

\begin{abstract}
Hospital statistics on morbidity and mortality are essential in assessing disease burden, evaluation of health policies and health planning. The study aimed to determine the morbidity pattern and short-term outcome among medical admissions in the Niger Delta University Teaching Hospital (NDUTH), Bayelsa State, Nigeria. This retrospective 7-years disease audit was carried out in the medical wards of NDUTH, Bayelsa State, Nigeria. Information extracted included name and gender of patients, diagnoses and disease outcomes. One thousand, one hundred and twenty five $(60.5 \%)$ females and seven hundred and thirty three (39.5\%) males had complete records and were therefore used for the analysis. The mean age of the patients was $50.14 \pm 16.66$ years with males being older $(\mathrm{p}<0.001)$. Non-Communicable Diseases (NCDs) accounted for a majority of cases $(1270 ; 68.4 \%)$ while 588 (31.6\%) were Communicable Diseases (CDs) NCDs were more prevalent among
\end{abstract}

Correspondence: Oghenekaro Godwin Egbi, Department of Internal Medicine, Niger Delta University Teaching Hospital, Okolobiri, Bayelsa State, Nigeria

Tel.: +234.8036583634

E-mail: drkoge@yahoo.com

Key words: Communicable diseases; non-communicable diseases; medical admissions; hospital; Nigeria.

Availability of data and materials: All data generated or analyzed during this study are included in this published article.

Ethics approval and consent to participate: Ethics approval for the study was obtained from the Research Ethical Committee (REC) of the Niger Delta University Teaching Hospital, Okolobiri with protocol no: NDUTH/REC/2020/10123. The study is conformed with the Helsinki Declaration of 1964, as revised in 2013, concerning human and animal rights.

Informed consent: Not applicable.

Received for publication: 7 April 2021.

Revision received: 29 April 2021.

Accepted for publication: 29 April 2021.

This work is licensed under a Creative Commons Attribution NonCommercial 4.0 License (CC BY-NC 4.0).

(C) Copyright: the Author(s), 2021

Licensee PAGEPress, Italy

Annals of Clinical and Biomedical Research 2021; 2:145

doi:10.4081/acbr.2021.145 males and older individuals $(\mathrm{p}<0.03 ; \mathrm{p}<0.001)$ and showed a rising trend over the years. CDs were however the leading cause of morbidities among females. The commonest diagnoses among males were retroviral disease, stroke, heart failure, pulmonary tuberculosis, diabetes and renal disease with women showing a similar trend except that heart failure replaced stroke as the second commonest morbidity while stroke came third, followed by diabetes, renal disease and hypertension. The all-cause mortality rates were $10.6 \%$ and $15.9 \%$ for females and males respectively. The major causes of mortality were infectious diseases and circulatory disorders for both genders. About 6.4\% males and 3.8\% females Left Against Medical Advice (LAMA). The pattern shows a rising prevalence of NCDs. Although CDs witnessed some decline, it however remained prevalent. The mortality rate was high while a good proportion LAMA. There is a need for strategic health programs to address this increasing tide of NCDs in our society, control CDs, and improve patient care while reducing mortality.

\section{Introduction}

Hospital based morbidity and mortality records are important because they give an idea of the health status and the diseases that are prevalent in a particular location or community. This is useful for policy makers, epidemiologists, public health specialists and other stakeholders in the health care industry in the planning, allocation and management of resources for health services, research training and development. ${ }^{1}$ This is particularly important in developing countries like Nigeria where population based studies are rarely available and where the health system is plagued with inadequate allocation of resources in a context of poor health indices, continuous currency devaluation and poor socio-economic and infrastructural development. ${ }^{2}$ A regular audit of cases will help to establish a trend for these diseases so that efforts and priority can be properly channeled. Medical cases have been shown to constitute $22 \%$ to $40 \%$ of all hospital admissions ${ }^{3-5}$ and account for the most common causes of death in hospitals. ${ }^{6}$ Studies have also shown high levels of adult mortality in the Sub-Saharan Africa (SSA) compared with reports from developed countries. ${ }^{7}$ Africa including Nigeria currently experiencing the epidemiologic transition, has witnessed a rise in the prevalence of Non-Communicable Diseases (NCDs) such as hypertension, diabetes mellitus, malignancies, cerebrovascular diseases, coronary heart disease, congestive heart failure, and chronic kidney disease in recent years. ${ }^{8}$ This is in spite of the fact that Communicable Diseases (CDs) have continued to prevail in these climes with occasional degeneration into outbreaks and epidemics. This implies that these regions now suffer from a double burden of diseases. ${ }^{9}$ The World Health Organization (WHO) had predicted that by 2020 , the causes of disease and deaths in SSA would have undergone a significant shift from CDs to NCDs). ${ }^{10}$ 
The aim of this study was to determine the pattern and shortterm outcomes of adult medical admissions in the Niger Delta University Teaching Hospital (NDUTH), a tertiary hospital in the Niger Delta region of Nigeria. Although there have been a few similar studies involving some hospitals in Nigeria, this is the first study among medical admissions in NDUTH, to the best of the author's knowledge. Considering the peculiarities in the Niger Delta area including oil exploration, gas flaring and environmental pollution, it is possible that the pattern of morbidities and mortalities may differ from what obtains elsewhere. It would also be useful to observe the trend in disease prevalence over the years.

\section{Materials and Methods}

The study was carried out in the Niger Delta University Teaching Hospital in Okolobiri, Bayelsa State. Bayelsa is an oil rich state occupying a prominent position in the Niger Delta region of Nigeria with a population of about 2 million residents. This tertiary hospital serves as a referral centre for primary and secondary health facilities in Bayelsa and neighbouring states. It is currently the only teaching hospital in the state and hosts students of the Niger Delta University (NDU) located in Amassoma, a nearby community. The hospital also runs a postgraduate residency programme for various specialties and sub-specialties, including internal medicine with several consultants in various fields. Sub-specialty services rendered in internal medicine include cardiology, neurology, nephrology, infectious disease, gastroenterology, dermatology and respiratory medicine.

Patients requiring in-patient care beyond 24 hours are admitted from the accident and emergency centre into the 40-bedded combined medical ward having a male and female section. There is also a separate 10-bedded isolation ward for infectious cases. Patients may also be admitted directly from the out-patient department into the wards.

The study design was retrospective and involved a review of case notes of adult patients that were admitted into the medical wards of the hospital between January 2013 and December 2019. Patients less than 15-years-old (considered under the pediatric age group) and those with incomplete records were also excluded from the study.

Case notes were made available on request from the Records Department of the hospital. Patient's age, sex and diagnosis were extracted from the records. A total population study within the period under review was intended. However, because of incomplete documentation, a purposive sampling of all admissions with complete data in the male and female medical wards was eventually done. Data was subsequently entered and stored in an SPSS spread sheet.

To allow for uniformity and standardization, the International Statistical Classification of Diseases (ICD-10) with the three-digit coding system was used to classify the diseases in this study. ${ }^{11}$ Diagnosed diseases were classified into CDs and NCDs. Non-communicable diseases were further classified on the basis of the affected systems. For instance, hypertension, heart failure, stroke and related conditions was grouped under Diseases of the circulatory system. Obesity, Diabetes Mellitus (DM), thyroid disease, etc. were group under Endocrine, Nutritional and Metabolic diseases while peptic ulcer, Gastro Esophageal Disease (GERD), diarrheal illnesses, liver, biliary and pancreatic diseases were classified under Gastrointestinal system (GIS) diseases. Diseases caused by micro-organisms such as bacteria, viruses, spirochaetes, helminths etc. were grouped under Certain infectious and parasitic diseases.
Pneumonias and other chest-related medical illnesses was categorized under Diseases of Respiratory System while kidney disease and related disorders were classified under Diseases of the genitourinary system. The diagnosis made by the supervising consultant or the most senior doctor in the unit after corroboration with the relevant laboratory or radiological investigation was the one used. For patients having multiple co-morbidities, the indication for admission was considered as the primary diagnosis while for those who had multiple admissions, each individual admission was considered as a separate one.

For the purpose of the study, patients' age was categorized into three groups: younger age ( $<45$ years old), middle age ( $45-65$ years old) and elderly ( $>65$ years old). Also, disease outcome was categorized as follows: Discharged, died, referred, transferred and Left Against Medical Advice (LAMA).

\section{Ethical consideration}

Ethics approval for the study was obtained from the Research Ethical Committee (REC) of the Niger Delta University Teaching Hospital, Okolobiri with protocol no: NDUTH/REC/2020/10123. Personal identifiable information such as names were avoided during the data entry process and alternatives such as serial numbers used in its stead. All data retrieved was kept privately and with strict confidentiality. To protect from unauthorized use, electronic data was password-protected and encrypted.

\section{Data analysis}

Data was analysed using IBM Statistical Product and Service Solutions (SPSS) version 20.0. Simple descriptive statistical analysis was performed including measures of dispersion such as mean, standard deviation and range. Differences between means of quantitative variables such as age, was analysed using the independent $t$ test. Frequency and cross-tabulation were used for categorical data and differences between groups analysed with chi square. Results were presented in forms of tables and charts. A p-value of $<0.05$ was considered significant.

\section{Results}

\section{Characteristics of participants}

There were 1858 admitted patients with available data out of which females comprised 1125 (60.5\%) while males were 733 (39.5\%). No record of admitted male patients was however found for the year 2014. The mean age of the patients was $50.14 \pm 16.66$ years (males was $52.67 \pm 16.44$, females was $48.49 \pm 11.25$ ) with ages ranging from 15-98 years. Males were significantly older than females $(\mathrm{t}=5.328, \mathrm{p}<0.001)$. Seven hundred and fifty one patients (40.4\%) were young, $745(40.1 \%)$ were middle aged while the remaining $362(19.5 \%)$ were elderly.

\section{Pattern of diseases}

NCDs accounted for a vast majority of diagnoses (1270; $68.4 \%$ ) while 588 (31.6\%) diagnoses were CDs. Although NCDs were prevalent across both genders, it was more among males $(\mathrm{p}=0.03)$. CDs were the leading cause of morbidities among females. All age groups also had a high prevalence of NCD, but it was more common in older individuals $(p<0.001)$ Table 1 .

The common diagnoses reported among the male patients were retroviral disease, stroke, heart failure, DM, pulmonary tuberculosis and renal disease. The trend was quite similar for women except that heart failure replaced stroke as the second most com- 
mon morbidity with stroke coming third and DM, renal disease and hypertension following in that order. The miscellaneous causes included other causes grouped together for the purpose of this study (Table 2).

The classification of the morbidities encountered according to ICD-10 category is shown in Table 3 . Infectious and parasitic diseases constituted the highest disease burden among females in 385 $(34.2 \%)$ with diseases of the circulatory system coming next (344; $30.6 \%$ ). On the other hand, diseases of the circulatory system were the most common among males, found in 254 (34.7) closely followed by infectious/parasitic diseases in 204 (27.8\%). For both gender, infectious/ parasitic diseases and diseases of the circulatory system put together accounted for up to three-fifth of total cases. Diseases of the digestive system, endocrine/nutritional/metabolic diseases as well as diseases of the genitourinary system were also commonly reported for both gender.

Diseases of skin and subcutaneous tissue and external causes of morbidity and mortality were rarely reported as causes of medical admission (Tables 3 and 4).

There was generally an increase in trend of NCDs across the years for both genders except for the years 2016/2017 where there was a sharp decline in rate for males (Figure 1) and 2016 for females (Figure 2).

\section{Short term outcome of patients}

Out of the 989 female patients who had their disease outcome documented, one hundred and five patients died while 107 males died out of 674 patients giving a mortality rate of $10.6 \%$ and $15.9 \%$ for females and males respectively with an overall mortality rate of $12.7 \%$. While $834(84.3 \%)$ females were discharged, $38(3.8 \%)$ left against medical advice. Similarly, while 513 (76.1\%) males were discharged, 43 (6.4\%) left against medical advice (Figure 3).

The major causes of mortality documented were infectious diseases $(47 ; 44.8 \%)$ and circulatory disorders $(26 ; 24.8 \%)$ for females and $37(34.6 \%)$ and $35(32.7 \%)$ for males respectively. All-cause mortality was significantly higher among males $\left(\mathrm{x}^{2}=9.965, \mathrm{p}=0.002\right)$.

The disease specific mortality rates among women were highest for retroviral disease $(45 ; 42.9 \%)$, followed by stroke $(19$; $18.1 \%)$, congestive cardiac failure $(9 ; 8.6 \%)$, chronic kidney disease $(7 ; 6.7 \%)$ and DM $(6 ; 5.7 \%)$. Patients who died from HIV (mean age $40.09 \pm 8.36$ years) and congestive cardiac failure (mean age $41.14 \pm 17.08$ years) were significantly younger than those dying from stroke (mean age $54.53 \pm 16.25$ years) and CKD (mean age $47.60 \pm 17.27$ years)

The major causes of mortality among males were retroviral disease $(27 ; 25.2 \%)$, stroke $(20 ; 18.7 \%)$, chronic liver disease, $(9$; $8.4 \%$ ), congestive heart failure $(8 ; 7.4 \%)$, diabetes $(7 ; 6.5 \%)$, pulmonary tuberculosis $(7 ; 6.5 \%)$ and chronic kidney disease $(7 ;$ $6.5 \%$ ). Male patients who died from HIV (mean age 44.63 \pm 9.904 ) were also significantly younger than those dying from stroke with mean age of $64.75 \pm 18.90$ years $(\mathrm{p}<0.001)$.

Table 1. Disease category in relation to age group and gender.

\begin{tabular}{|c|c|c|c|c|}
\hline Variable & Total & $\begin{array}{c}\text { CD } \\
\text { Category (\%) }\end{array}$ & $\begin{array}{c}\text { NCD } \\
\text { Category (\%) }\end{array}$ & p-value \\
\hline \multicolumn{5}{|l|}{ Age group } \\
\hline Young & 751 & $359(47.8)$ & $392(52.2)$ & $<0.001 *$ \\
\hline Middle aged & 745 & $177(23.8)$ & $568(76.2)$ & $<0.001^{*}$ \\
\hline Elderly & 362 & $52(14.4)$ & $310(85.6)$ & $<0.001^{*}$ \\
\hline \multicolumn{5}{|l|}{ Gender } \\
\hline Male & 733 & $203(27.7)$ & $530(72.3)$ & $0.03^{*}$ \\
\hline Female & 1125 & $385(34.2)$ & $740(65.9)$ & $0.03^{*}$ \\
\hline
\end{tabular}

CD: Communicable Diseases; NCD: Non-Communicable Diseases; $\chi^{2}$ : chi-square.

Table 2. The causes of morbidities among the patients.

\begin{tabular}{lccc} 
Diagnosis & Total n (\%) & Male n (\%) & Female n (\%) \\
Retroviral disease & $385(20.7)$ & $96(13.3)$ & $289(25.7)$ \\
Stroke & $219(11.8)$ & $94(12.7)$ & $125(11.1)$ \\
\hline Heart failure & $217(11.7)$ & $82(11.1)$ & $135(12.0)$ \\
Diabetes & $180(9.7)$ & $67(9.1)$ & $113(10.0)$ \\
\hline Hypertension with emergencies & $115(6.2)$ & $43(5.9)$ & $72(6.4)$ \\
Pulmonary tuberculosis & $139(7.5)$ & $80(10.9)$ & $59(5.3)$ \\
\hline Renal disease & $118(6.4)$ & $44(6.0)$ & $74(6.6)$ \\
Chronic liver disease & $73(3.9)$ & $38(5.2)$ & $35(3.1)$ \\
\hline Sepsis & $47(2.5)$ & $24(3.3)$ & $23(2.1)$ \\
Miscellaneous* & $365(19.6)$ & $165(22.5)$ & $200(17.7)$ \\
\hline Total & $1858(100.0)$ & $733(100.0)$ & $1125(100.0)$ \\
\hline
\end{tabular}

*Miscellaneous includes less commonly encountered diseases grouped together such as malaria, gastroenteritis, peptic ulcer disease, meningitis, alcohol and drug related conditions, asthma, chronic obstructive airway disease, sickle cell disease, hematologic malignancy, etc. for the purpose of the study. 


\section{Discussion}

Our findings of cardiovascular and infectious diseases as the overall most common cause of medical admission in this study agree with previous reports. ${ }^{2,12}$ Also, circulatory disorders ranked highest among men and was closely followed by infectious diseases. It is believed that men develop cardiovascular disease at a younger age, compared with women, a phenomenon that is partly explained by a protective effect of female sex hormones during premenopausal life. ${ }^{13}$ On the other hand, infectious diseases constituted the highest burden of female medical admissions with HIV being largely responsible. The higher prevalence of HIV infection among females compared with males in many regions has been reported since the onset of the HIV epidemic. ${ }^{14}$ Gender inequalities in prevalence has been attributed to the differences in distribution of predisposing factors. For instance in SSA, the lower socio-economic status of women, the greater tendency to be uneducated and unemployed, unequal power relationship and subordinate positions and other socio-cultural factors such as increased likelihood of receptive intergenerational sex, abuse and rape have all contributed to the increased spate of the infection among the female populatioo. ${ }^{15}$ Even though SSA is home to only $12 \%$ of the global population, it is said to account for up to $71 \%$ of the global burden of HIV infection. ${ }^{16}$ Pulmonary tuberculosis was second to HIV as a leading cause of infectious disease for both genders in the population. TB was also the most common co-morbid infection observed in the HIV patients. This deadly duo of tuberculosis with HIV infection is recognized in literature. ${ }^{17}$ Despite the fact that malaria is endemic in our environment, it was not commonly reported. This is possibly because most cases of adult malaria are treated on an out-patient basis and are only seldom admitted except for severe cases.

Akoria et al. also reported cardiovascular disease as being next to HIV infection among females. ${ }^{12}$ In that study, heart failure was the most common cardiovascular morbidity reported among females while stroke was the leading cause of morbidity among males in keeping with our findings. Age-specific stroke rates are known to be generally higher in men until much later in life when gender differences tend to equalize. ${ }^{18}$ In South Africa, cardiovascular disease was identified as the second leading cause of death after HIV accounting for up to $40 \%$ of deaths among adults. ${ }^{19}$ It has long been projected that developing nations including African countries will account for the major part of the increase in cardiovascular disease prevalence worldwide. ${ }^{20}$

The study shows a double burden of diseases but with a relative increase in NCDs compared with CDs over the study period. The reason for this reported decline is not clear. The changing epidemiologic transition in Africa, including Nigeria has seen cardiovascular diseases gradually replace infectious disease as the leading cause of morbidity and mortality in communities. ${ }^{21}$ There was

Table 3. Classification of diseases encountered according to the ICD 10 classification.

\begin{tabular}{|c|c|c|c|}
\hline ICD 10 disease Classification & Total & Male n (\%) & Female n (\%) \\
\hline Infectious and parasitic diseases & $588(31.6)$ & 204(27.8) & $384(34.1)$ \\
\hline Diseases of Nervous system & $34(1.8)$ & $13(1.8)$ & 21(1.9) \\
\hline Diseases of Digestive system & $142(7.6)$ & $61(8.3)$ & $81(7.2)$ \\
\hline Diseases of Respiratory system & $47(2.5)$ & $25(3.4)$ & $22(2.0)$ \\
\hline Diseases of circulatory system & $599(32.2)$ & 254(34.5) & $345(30.7)$ \\
\hline Supplementary factors related to morbidity and mortality not classified elsewhere & $2(0.1)$ & 127(6.8) & $2(0.3)$ \\
\hline Diseases of genitourinary system & $49(6.7)$ & $0(0.0)$ & $78(6.9)$ \\
\hline Endocrine, nutritional and metabolic diseases & 194(10.4) & $75(10.2)$ & $119(10.6)$ \\
\hline Mental and behavioural disorders & $22(1.2)$ & 14(1.9) & $8(0.7)$ \\
\hline Diseases of blood and blood forming organs & $41(2.2)$ & $17(2.3)$ & $24(2.1)$ \\
\hline Diseases of musculoskeletal system \& connective tissue & $20(1.1)$ & $4(0.5)$ & $16(1.4)$ \\
\hline Malignant Neoplasm & $23(1.2)$ & $12(1.6)$ & $11(1.0)$ \\
\hline External causes of morbidity and mortality & $4(0.2)$ & $1(0.1)$ & $3(0.3)$ \\
\hline Symptoms and signs and abnormal clinical and laboratory findings & $8(0.4)$ & $1(0.1)$ & $7(0.6)$ \\
\hline Diseases of skin and subcutaneous tissue & $7(0.4)$ & $6(0.5)$ & $1(0.1)$ \\
\hline Total & $733(39.5)$ & $6(0.5)$ & 1125 \\
\hline
\end{tabular}

n: frequency.

Table 4. Disease-specific mortalities for the most common diseases among male and female patients.

\begin{tabular}{lccc} 
Disease & Total & Mortality & Female n (\%) \\
Retroviral disease & $72(40.9)$ & Male n (\%) & $45(49.5)$ \\
Stroke & $39(22.2)$ & $27(31.8)$ & $19(20.9)$ \\
\hline Congestive heart failure & $17(9.7)$ & $20(23.5)$ & $9(9.9)$ \\
Chronic kidney disease & $14(8.0)$ & $8(9.4)$ & $7(7.7)$ \\
\hline Diabetes & $13(7.4)$ & $7(6.5)$ & $6(6.6)$ \\
chronic liver disease & $12(6.8)$ & $7(8.2)$ & $3(3.3)$ \\
\hline Pulmonary tuberculosis & $9(5.1 \%)$ & $9(10.6)$ & $2(2.2$ \\
Total & $176(100.0)$ & $7(8.2)$ & $91(100.0)$ \\
& & $85(100.0)$ & \\
\hline
\end{tabular}


spiritual attacks. ${ }^{33}$

This study brings to limelight the poor health record-keeping characteristic of health institutions in Nigeria as no data was found for an entire year among admitted males. This may partly explain the smaller number of males in the study. It is likely though that entry had been made but overtime the books had become mutilated or damaged. This buttresses the need for digital storage of data in medical records department of hospitals. Advantages of electronic records include less susceptibility to physical wear and tear and lower requirement for manpower. Others include reduced medical errors, financial and operational benefits, compactness of data, ease of access to information and improved ability to conduct research. ${ }^{37}$ Unfortunately however, the use of paper filing, with all its flaws still dominates the record keeping system in most hospitals in Nigeria. Factors that have been adduced to this may include high upfront acquisition costs of digital equipment, ongoing maintenance costs, and disruptions to workflows resulting from need to learn a new system and reluctance to change among staff. ${ }^{12,37}$

The study however had some limitations. Since the study design was retrospective in nature, we could only make use of data that had been pre-collected. There were cases of incomplete information and missing data. Certain information of potential interest such as the duration of admission for the patients were not captured in the study. The causes of mortality were clinically determined by the doctor who certified the patient dead in most cases without a post-mortem examination.

\section{Conclusions}

In conclusion, we have done a 7-years audit of the admitted medical cases in a tertiary hospital in Bayelsa State. The most commonly reported diseases were HIV/AIDS, stroke, heart failure, chronic liver disease and renal disease. The study has shown an increasing toll from NCDs over the years while CDs have continued to remain a burden. Another disturbing finding is the high rate of LAMA and mortality among admitted patients. There is therefore need for government and other stakeholders of the Nigerian health care industry to put strategic measures in place at all levels of health care for the prevention and prompt management of cardiovascular and other non-communicable diseases to reduce mortality while strengthening the already existing infection control policies.

\section{References}

1. Myint PK, MacLullich AM, Witham MD. The role of research training during higher medical education in the promotion of academic medicine in the UK. Postgrad M J 2006;82:767-70.

2. Jamoh BY, Abubakar SA, Isa SM. Morbidity and mortality profile of patients seen in medical emergency unit of a teaching hospital in Nigeria: a 4- yr audit. Sahel Med J 2018;21:2137.

3. Ogun SA, Adelowo OO, Familoni OB, et al. Pattern and outcome of medical admissions at the Ogun State University Teaching Hospital, Sagamu-A three year review. West Afr J Med 2000;19:304-8.

4. Odenigbo CU, Oguejiofor OC. Pattern of medical admissions at the Federal Medical Centre, Asaba - A two year review. Niger J Clin Pract 2009;12:395-7.

5. Okunola OO, Akintunde AA, Akinwusi PO. Some emerging issues in medical admission pattern in the tropics. Niger J Clin
Pract 2012;15:51-4.

6. World Health Organization. New WHO report: Death from non-communicable diseases on the rise, developing world hit hardest. Moscow: WHO; 2011. Accessed 2020 Dec 12. Available from: http://www.who.int/mediacentre/news/releases/2011

7. Murray CJL, Yang G, Qiao X. Adult mortality: levels, patterns, and causes. In The Health of Adults in the Developing World. Feachem RGA, Kjellstrom T, Murray CJL, et al. eds. New York: Oxford University Press; 1992.

8. 1slam SMS, Purnat TD, Phuong NT, et al. Non communicable diseases (NCDs) in developing countries: a symposium report. Glob Health 2014;10:1-7.

9. Maher D, Smeeth L, Sekajugo J. Health transition in Africa: practical policy proposals for primary care. Bull World Health Organ 2010;88:943-8.

10. Agyei-Mensah S, de-Graft Aikins A. Epidemiological transition and the double burden of disease in Accra, Ghana. J Urban Heal Bull New York Acad Med 2010;87:879-97.

11. World Health Organization. International Statistical Classification of diseases and related health problems. 10th revision. 2010;2:1-201.

12. Akoria OA, Unuigbe EI. A 6-Month Review of Medical Admissions in a Nigerian Teaching Hospital. Int J Health Res 2009;2:125-30

13. Lorenzo C, Williams K, Hunt KJ, Haffner SM. The National Cholesterol Education Program - Adult Treatment Panel III. International Diabetes Federation and World Health Organization definitions of the metabolic syndrome as predictors of incident cardiovascular disease and diabetes. Diabetes Care 2007;30:8-13.

14. Girum T, Wasie A, Lentiro K, et al. Gender disparity in epidemiological trend of HIV/AIDS infection and treatment in Ethiopia. Arch Public Health 2018;76:51.

15. Sia D, Onadja Y, Hajizadeh M. What explains gender inequalities in HIV/AIDS prevalence in sub-Saharan Africa? Evidence from the demographic and health surveys. BMC Public Health 2016;16:1136.

16. Eze CO, Agu CE, Kalu UA, et al. Pattern of Medical Admissions in a Tertiary Health Centre in Abakaliki SouthEast Nigeria. J Biol Agricult Healthcare 2013;3:90-4.

17. Pai-Dhungat JV, Parikh FJ. HIV/TB--an unholy alliance'. Assoc Physicians India 2007;55:457

18. Andersen KK, Andersen ZJ, Oslen TS. Age and gender specific prevalence of cardiovascular risk factors in 40,102 patients with first-ever ischemic stroke: a nationwide Danish study. Stroke 2010;41:2768-74.

19. Peer N, Steyn K, Dennison CR, et al. Determinants of target organ damage in black hypertensive patients attending primary health care services in Cape Town: the Hi-Hi study. Am J Hypertension 2008;21:896-902.

20. Reddy KS, Yusuf S. Emerging epidemic of cardiovascular disease in developing countries. Circulation 1998;97:596-601.

21. Mbewu A, Mbanya JC. Cardiovascular disease. In: Jamison DT, Feachem RG, Makgoba MW, et al. eds. Disease and mortality in Sub-Saharan Africa. 2nd edition. Washington (DC): The International Bank for Reconstruction and Development / The World Bank; 2006. Chapter 21. Available from: https://www.ncbi.nlm.nih.gov/books/NBK2294/

22. Ike SO. The pattern of admissions into the medical wards of the University of Nigeria Teaching Hospital, Enugu (2). Niger J Clin Pract 2008;11:185-92.

23. UNAIDS AIDSinfo. Country fact sheets. Nigeria HIV and 
AIDS estimate 2019. Accessed 11th Feb 2021. Available at https://www.unaids.org/en/regionscountries/countries/nigeria

24. Mathers CD, Loncar D. Projections of global mortality and burden of disease from 2002 to 2030. PLoS Med 2006;3:e442.

25. Oguejiofor O, Odenigbo C, Onwukwe C. Diabetes in Nigeria: impact, challenges, future directions. Endocrinol Metab Synd 2014;3:2.

26. International Diabetes Federation. Diabetes Atlas 8th Edition 2017. 2017. Accessed 11 Feb 2021. Available from: http://www.diabetesatlas.org

27. Uloko AE, Musa BM, Ramalan MA, Gazawa ID, Puepet FH, Uloko AT et al. Prevalence and risk factors for diabetes mellitus in Nigeria: a systematic review and meta-analysis. Diabetes Ther 2018;9:1307-16.

28. Stanifer JW, Jing B, Tolan S, et al. The epidemiology of chronic kidney disease in Sub- Saharan Africa: A systematic review and meta- analysis. Lancet Glob Health 2014;2:e174-81.

29. Odenigbo CU, Oguejiofor OC. Pattern of medical admissions at the Federal Medical Centre, Asaba-a two year review. Niger J Clin Pract 2009;12:395-7.

30. Adeoti AO, Ajayi EA, Ajayi AO, et al. Pattern and Outcome of Medical Admissions in Ekiti State University Teaching Hospital, Ado-Ekiti- A 5 Year Review. Am J Med Medical Sci 2015;5:92-8.
31. Arodiwe EB, Nwokediuko SC, Ike SO. Medical causes of death in a teaching hospital in South-Eastern Nigeria: A 16 year review. Niger J Clin Pract 2014;17:711-6.

32. Ezeala-Adikaibe BA, Aneke E, Orjioke C, et al. Pattern of medical admissions at Enugu state university of science and technology teaching hospital: a 5 year review. Ann Med Health Sci Res 2014;4:426-31.

33. Ogunmola AJ, Oladosu OY. Pattern and outcome of admissions in the medical wards of a tertiary health centre in a rural community of Ekiti State, Nigeria. Annals Afr Med 2014; 13:195-203.

34. Fadare JO, Babatunde OA, Olarenwaju T, Busari O. Discharge against medical advice: Experience from a rural Nigerian hospital. Ann Nigerian Med 2013;7:60-5.

35. Akande TM, Sekoni OO, Aderibigbe SA. Outcome of admission in a university teaching hospital in Nigeria. Adv Trop Med Pub Health Int 2012;2:72-8.

36. Yong TY, Fok JS, Hakendorf P, et al. Characteristics and outcomes of discharges against medical advice among hospitalized patients. Intern Med J 2013;43:798-802.

37. Menachemi N, Collum TH. Benefits and drawbacks of electronic health record systems. Risk Manag Health Policy 2011;4:47-55. 